\title{
O processo de recuperação de serviços em agências de turismo através da abordagem do sistema sócio-técnico
}

\section{The process of service recovery in travel agencies through a social-technical system approach}

\author{
Roberto Gualberto Dantas (DANTAS, R. G.) ${ }^{*}$ \\ Marlusa Gosling (GOSLING, M.) ${ }^{*}$ \\ Mariana de Freitas Coelho (COELHO, M. F.) ${ }^{* * *}$
}

\begin{abstract}
RESUMO - Este artigo aborda a importância do processo de recuperação de serviços para agências de turismo na perspectiva do prestador de serviços. O objetivo desse trabalho foi testar quantitativamente a aplicação do modelo de recuperação de serviços proposto por Smith, Fox e Ramirez (2010) no contexto de agências de turismo. Utilizou-se uma abordagem sócio-técnica, a qual privilegia a participação dos funcionários da empresa na solução das falhas e busca analisar o trabalho como um todo ao considerar as tarefas, tecnologias, pessoas e estrutura como variáveis básicas e interdependentes. A pesquisa foi do tipo quantitativa, tendo sido realizada em agências de turismo da região Centro-Oeste de Minas Gerais, Brasil. Os dados foram coletados em 2011 por meio de questionários estruturados. Dentre os resultados, tem-se que a existência de um elevado grau de confiança proporciona o retorno positivo dos clientes em relação ao desempenho pessoal dos funcionários da empresa no processo de recuperação de um serviço.
\end{abstract}

Palavras-chave: Marketing de Serviços; Recuperação de Serviços; Sistema SócioTécnico; Agências de Turismo.

ABSTRACT - This paper discusses the importance of the service recovery process for travel agencies through the perspective of the service providers. The aim of this study was to test quantitatively the service recovery model proposed by Smith, Fox and Ramirez (2010) among the context of travel agencies. A socio-technical approach was used, which emphasizes the participation of company employees in solving failures. It also analyzes the service as a whole, by considering the tasks, technologies, people and structure as basic and interdependent variables. The research was quantitative, been held on tourism agencies of the central-west of Minas Gerais, Brazil. Data were collected

\footnotetext{
* Graduação em Administração e Especialização em Marketing pela Faculdade de Ciências Econômicas, Administrativas e Contábeis de Divinópolis (FACED) e Mestrado em Administração pela Faculdade de Estudos Administrativos de Minas Gerais (FEAD - MG). Professor do curso de Administração da Universidade de Itaúna - UI. Endereço para correspondência: Praça do Mercado, 191. CEP: 35500-048 Divinópolis - Minas Gerais (Brasil). Telefone para contato: 37 3512-2019. E-mail: rdantas@uit.br

** Graduação em Ciência da Computação (bacharelado), Mestrado em Administração e Doutorado em Administração pela Universidade Federal de Minas Gerais (UFMG). Professora Adjunta II da UFMG. Endereço para correspondência: Av. Antônio Carlos, 6627. CEP: 31270-901 - Belo Horizonte - Minas Gerais (Brasil). Telefone para contato: 31 3409-7050. E-mail: mg.ufmg@ gmail.com

*** Graduação em Turismo e Especialização em Avaliação, Gestão e Elaboração de Projetos Sociais pela UFMG. Mestranda em Administração pela UFMG. Professora Bolsista do Curso de Design de Moda da UFMG. Endereço para correspondência: Av. Antônio Carlos, 6627. CEP: 31270-901 - Belo Horizonte Minas Gerais (Brasil). Telefone para contato: 31 3409-7050. E-mail: marifcoelho@gmail.com
} 
through structured questionnaires. Among the results, the existence of a high degree of trust provides the positive feedback from customers regarding the performance of the personal staff of the company in the service recovery process.

Key words: Service marketing; Service Recovery; Social Technical System; Tourism Agencies. 


\section{INTRODUÇÃO}

A definição de serviços é abordada sob diversas perspectivas na literatura. Hoffman e Bateson (2003) analisam a dificuldade de se determinar o que se poderia chamar de serviço puro, ou seja, aquele que é intangível (não pode ser tocado, visto, ouvido, cheirado ou provado); inseparável (são produzidos e consumidos simultaneamente); heterogêneo (depende exclusivamente de quem presta o serviço); e perecível (não pode ser estocado). Deste modo, os autores caracterizam os serviços como ações, esforços ou desempenhos.

De acordo com o dicionário da Associação Americana de Marketing ${ }^{1}$, serviços são produtos que são totalmente ou substancialmente intangíveis; e também atividades realizadas por vendedores e outros que acompanham a venda de um produto e ajudam na sua troca ou na sua utilização. Já para Grönroos (2009) o conceito de serviço é um fenômeno complicado, com muitos significados e com um escopo muito amplo. Segundo o autor, praticamente qualquer produto físico pode ser transformado em um serviço, sendo necessário que o vendedor despenda esforços para adequar o produto à necessidade ou exigências pormenorizadas do seu cliente. Conceitos lúdicos também foram amplamente utilizados para se caracterizar serviço. Gummesson (1987) define que um serviço é algo que pode ser comprado e vendido, mas que não pode ser derrubado no chão. Grönroos (2009), em crítica a esses conceitos, salienta que desde a década de 1980 já não existe tanta preocupação em se definir serviços, e apresenta a seguinte definição:

Um serviço é um processo, consistindo em uma série de atividades mais ou menos intangíveis que, normalmente, mas não necessariamente sempre, ocorrem interações entre o cliente e os funcionários de serviço e/ou recursos ou bens físicos e/ou sistemas de fornecedores de serviços e que são fornecidas como soluções para problemas dos clientes. (GRÖNROOS, 2009, p. 46).

Por outro lado, ao definir o serviço como um processo, torna-se inerente a possibilidade de existir falhas entre consumidores e prestadores de serviço (ZEITHAML; BITNER, 2000), gerando insatisfação dos consumidores quando há uma

Dicionário da Associação Americana de Marketing. Disponível em: <http://www.marketingpower.com/_layouts/Dictionary.aspx?dLetter=S> Acesso em: 02/05/2013. 
resposta inapropriada dos funcionários à falha ocorrida. Nesse contexto, a resolução satisfatória de reclamações de clientes sobre os serviços de uma empresa tem se apresentado como uma tarefa desafiadora para muitas empresas de serviços (PRANIC; ROEHL, 2012). Ainda, a recuperação de serviços é um fator estratégico para as firmas (SANTOS; FERNANDES, 2008) e direciona a lealdade de clientes, boca-a-boca positivo, compra de outros produtos do portfólio da empresa e consequentemente afeta o desempenho financeiro em longo prazo (PRANIC; ROEHL, 2012).

Essa importância da recuperação de serviços para o relacionamento entre cliente e empresa, justifica o aprofundamento do estudo de recuperações de serviços, sobretudo, em setores pouco estudados como o turismo. Além disso, é escassa a literatura que relaciona a recuperação de serviços com a abordagem sócio-técnica, a qual aborda a participação dos funcionários da empresa na solução das falhas nas perspectivas social e técnica. De acordo com Smith, Fox e Ramirez (2010) a abordagem sócio-técnica considera que funcionários com atitudes distintas, crenças e reações ao arranjo empresarial (sistema social) usam ferramentas, técnicas e conhecimento organizacional (sistema técnico) para a recuperação de serviços.

O objetivo desse trabalho foi o de testar quantitativamente o modelo de recuperação de serviços proposto por Smith, Fox e Ramirez (2010) adaptado ao contexto de agências de turismo. Nesse sentido, aprofunda-se a abordagem dos autores para o setor turístico, contribuindo para a confirmação do modelo em um ambiente operacional específico. Ainda, este trabalho teve como propósito contribuir para o entendimento de como organizações intermediárias no oferecimento de serviços podem atuar em seu sistema de recuperação de serviços.

\section{REVISÃO DE LITERATURA}

O marketing de serviços embasa esse trabalho, considerando a premissa de que as agências de turismo devem prestar serviços e satisfazer as necessidades dos seus clientes. Também se discorre sobre a mensuração da qualidade através da satisfação do consumidor e as possíveis falhas de serviços. Finamente, aborda-se o sistema sócio- 
técnico, o qual abrange os funcionários e ferramentas organizacionais para a organização dos serviços. (SMITH; FOX; RAMIREZ, 2010).

\subsection{MARKETING DE SERVIÇOS}

Segundo Kotler (2009) o Marketing é uma tarefa que visa criar, promover e fornecer bens e serviços a clientes sejam estes pessoas físicas ou jurídicas. Já a Associação Americana de Marketing (2008), conceitua marketing como uma função organizacional e um conjunto de processos que envolvem a criação, a comunicação e a entrega de valor para os clientes, bem como a administração do relacionamento com os mesmos, e complementa a conceituação salientando a importância do benefício mútuo para a organização e seu público interessado.

O Marketing Mix, desenvolvido na década de 1950 por McCarthy (1960), conhecido e propagado como os 4Ps do Marketing, é amplamente utilizado como estratégia no marketing de serviços. Além de Preço, Praça, Produto e Promoção, outros 3Ps: Pessoas, Processo e Provas Físicas também foram incorporados às estratégias ligadas a serviço, totalizando 7 Ps do Marketing de Serviços (BITNER, BOOMS, e STANREAULT, 1990).

Desta forma, um estudo aprofundado do marketing de serviços deve abordar, obrigatoriamente, a análise do ambiente, da demanda, da oferta, do comportamento do consumidor de serviços e as estratégias de fidelização. Além disso, devem ser consideradas as estratégias de precificação e de comunicação, a mensuração da qualidade e a recuperação dos serviços. Contudo, a recuperação de serviços, continua sendo um dos temas menos explorados academicamente no marketing.

\subsection{MENSURAÇÃO DA QUALIDADE E RECUPERAÇÃO DOS SERVIÇOS}

No atual mercado, globalizado e competitivo, o apelo pela qualidade total tem guiado as ações administrativas na busca pela perfeição. Especificamente no setor de serviços, em função das suas características peculiares, a busca pela qualidade total é ainda mais acentuada e caracteriza um grande diferencial para as empresas. 
A diferenciação de um serviço pode se dar através de um dos 7P's do Marketing de Serviços e buscar a perfeita adequação da prestação do serviço à demanda do usuário (BITNER, BOOMS, e STANREAULT, 1990; LOVELOCK e WRIGHT, 2001). Segundo Las Casas (2006, p. 297), no setor de serviços é primordial diferenciar-se pela qualidade. Para Bateson e Hoffman (2001) o ideal é avaliar e melhorar o sistema de prestação de serviços para entregá-los de maneira impecável, sem interrupção, confusão ou inconveniência para o cliente, tendo, como resultado final, a plena satisfação do consumidor. Neste contexto, a mensuração da qualidade se dá pela mensuração da satisfação do cliente.

Tanto para consumo de produtos quanto de serviços, não se pode desprezar a importância da satisfação do cliente. Uma grande dificuldade encontrada, apesar da gama de estudos na área, é determinar corretamente o que é, ou quando se alcança a satisfação.

Um dos modelos utilizados para determinar a satisfação do cliente é o modelo de quebra das expectativas que, segundo Hoffman e Bateson (2003, p. 330) propõe comparar as expectativas do cliente com suas percepções. Caso suas expectativas sejam confirmadas (percepção igual expectativa), o cliente estará satisfeito. No caso de quebra das expectativas (percepção menor que expectativa), situa a insatisfação.

\section{QUADRO 1 - DEFINICÕES ALTERNATIVAS DE SATISFAÇÃO}

\begin{tabular}{|l|l|}
\hline Definição de déficit normativo & $\begin{array}{l}\text { Compara os resultados reais com os que são culturalmente } \\
\text { aceitáveis. }\end{array}$ \\
\hline Definição de equidade & $\begin{array}{l}\text { Compara os ganhos em um intercâmbio social - se os } \\
\text { ganhos forem desiguais, o perdedor ficará insatisfeito. }\end{array}$ \\
\hline Definição de padrão normativo & $\begin{array}{l}\text { As expectativas são baseadas no que o cliente acredita que } \\
\text { deve receber - a insatisfação ocorre quando o resultado } \\
\text { real é diferente da expectativa padrão. }\end{array}$ \\
\hline Definição de justeza de procedimento & $\begin{array}{l}\text { A satisfação é uma função da convicção do cliente que foi } \\
\text { tratado corretamente. }\end{array}$ \\
\hline
\end{tabular}

FONTE: adaptado de KEITH (1991).

Segundo Hoffman e Bateson (2003), a satisfação do cliente é uma das áreas mais estudadas do Marketing. Contudo, o estudo das falhas e da recuperação dos serviços, seus mecanismos e benefícios ainda é um tema pouco explorado. 
As falhas de serviço podem ser divididas em três categorias: (i) falha em função de erro no sistema; (ii) falha em função das necessidades dos clientes; e (iii) falhas em função da ação do prestador.

QUADRO 2 - CATEGORIZAÇÃO DAS FALHAS DE SERVIÇO

\begin{tabular}{|l|l|l|}
\hline \multirow{4}{*}{$\begin{array}{l}\text { Falha causada pelo } \\
\text { Sistema }\end{array}$} & Serviço Indisponível & Ausência de serviço normalmente disponível \\
\cline { 2 - 3 } & Serviço lento & $\begin{array}{l}\text { Quando o serviço se torna inexplicavelmente } \\
\text { vagaroso }\end{array}$ \\
\cline { 2 - 3 } $\begin{array}{l}\text { Falha causada pelo } \\
\text { Cliente }\end{array}$ & Outras falhas & $\begin{array}{l}\text { Outras falhas diversas causadas por erros no } \\
\text { sistema }\end{array}$ \\
\cline { 2 - 3 } & Necessidades implícitas & $\begin{array}{l}\text { Necessidades que não foram devidamente } \\
\text { explicadas pelo cliente }\end{array}$ \\
\cline { 2 - 3 } & Necessidades especiais & $\begin{array}{l}\text { Modificação do serviço para atender necessidades } \\
\text { especiais dos clientes }\end{array}$ \\
\cline { 2 - 3 } & Erro do cliente & $\begin{array}{l}\text { Modificação do serviço para atender a preferência } \\
\text { do cliente }\end{array}$ \\
\cline { 2 - 3 } Falha causada pelo clientes & $\begin{array}{l}\text { Falhas desencadeadas por erros admitidos pelo } \\
\text { cliente }\end{array}$ \\
\hline Funcionário & Perturbação de outros clientes & $\begin{array}{l}\text { Falhas provocadas pela influência negativa de } \\
\text { outros clientes }\end{array}$ \\
\cline { 2 - 3 } & Nível de atenção & $\begin{array}{l}\text { Falhas causadas pela falta ou excesso de atenção } \\
\text { do funcionário }\end{array}$ \\
\cline { 2 - 3 } & Ação inusitada & $\begin{array}{l}\text { Falhas causadas pela atitude incomum do } \\
\text { funcionário }\end{array}$ \\
\cline { 2 - 3 } & Gestalt & $\begin{array}{l}\text { Ação do pessoal de serviço que violem as normas } \\
\text { culturais da sociedade }\end{array}$ \\
\cline { 2 - 3 } & Avaliação holística da situação e/ou do cliente \\
\cline { 2 - 3 } & Condições adversas & $\begin{array}{l}\text { Falhas causadas por situações que estressantes } \\
\text { para o funcionário }\end{array}$ \\
\hline
\end{tabular}

FONTE: Adaptado de HOFFMAN e BATESON (2003, p. 393-395).

Um serviço pode ser considerado falho quando, por qualquer motivo, gera algum tipo de insatisfação para o cliente (BITNER, 1990). Quando ocorrem falhas, as relações entre prestador e usuário dos serviços tendem a ficar vulneráveis ou até se extinguirem. Além do impacto negativo na imagem da empresa causado pelo 'boca-a-boca' negativo, também pode impactar negativamente no resultado financeiro da empresa, em função do aumento do custo causado pela falta de qualidade.

Diversos autores como Zeithaml, Berry e Parasuraman (1996), Grönroos (2000), Hoffman e Bateson (2003) e Las Casas (2006) concordam que é da empresa a responsabilidade de identificar e corrigir as falhas nos serviços. Esta correção deve, obrigatoriamente, observar e atender as expectativas do cliente quanto à solução dos seus problemas. Para Berry (1996), muitas vezes o processo de recuperação do serviço tem um impacto maior na satisfação do consumidor do que o próprio serviço. 
Segundo Grönroos (2000, p. 112), o procedimento de recuperação do serviço pode ser decomposto em três partes de acordo com a percepção do cliente, descrevendo aspectos diferentes de quão justo ou injusto o processo é considerado pelo cliente.

1- Equidade distributiva: o grau em que o resultado do processo de recuperação de serviços é igual ao que o cliente pensa que merece ou precisa. 2- Equidade procedural: o grau em que os clientes sentem que podem influenciar o processo de recuperação.

3- Equidade interativa: o grau em que os clientes consideram que as interações interpessoais durante o processo são justas.

O principal fator que justifica o estudo de estratégias de recuperação de serviços é o fato de que nenhum serviço está livre de falhas. Embora a adoção da recuperação dos serviços como estratégia corrente na empresa exponha a falibilidade dos seus processos, diversos estudos na área indicam que a adoção deste tipo de estratégia tem por justificativa e consequente resultado, a geração de resultados positivos para os clientes. Tax, Brown e Chandrashekaran (1998) salientam que a recuperação dos serviços gera um elevado grau de satisfação, retenção e lealdade dos clientes.

Para Liao e Chuang (2004), é fundamental o empowerment dos funcionários, principalmente os de linha de frente, uma vez que lidam diretamente com as falhas e necessitam de autonomia para solucionar o problema do cliente. Portanto, funcionários precisam estar cientes de seu importante papel ao buscar a recuperação de um serviço.

Ao considerar a responsabilidade da empresa pela recuperação do serviço, idealizou-se o estudo do processo de recuperação dos serviços pela perspectiva do prestador do serviço através da abordagem do sistema sócio-técnico.

\subsection{RECUPERAÇÃO DOS SERVIÇOS PELA ABORDAGEM DO SISTEMA SÓCIO- TÉCNICO}

A história da escola sócio-técnica se iniciou em 1949, com o Tavistock Institute of Human Relations analisando problemas de mecanização de mineradoras inglesas de carvão (BIAZZI Jr.,1994). De acordo com o autor mencionado, o processo de extração de carvão foi analisado por Trist e Bamforth, buscando descrever e inter-relacionar o trabalho de mecanização das minas à luz de aspectos técnicos, organizacionais, sociais e psicológicos. 
A abordagem sócio-técnica foi então aprimorada por Emery e Trist (1965) e tem como um dos principais aspectos a participação dos funcionários da empresa na solução das falhas. Busca analisar o trabalho como um todo e considera as tarefas, tecnologias, pessoas e estrutura como variáveis básicas e interdependentes. Segundo Biazzi Jr. (1994), a organização na perspectiva sócio-técnica é um sistema aberto, que interage com o ambiente e é capaz de autorregulação. Através deste sistema é possível obter uma percepção mais realista de como o subsistema social e o subsistema técnico, atuando em conjunto, influenciam o ambiente e a organização.

Para Emery e Trist (1965), o subsistema técnico funciona como uma das condições limitativas do sistema social da empresa e tem um papel mediador entre os objetivos de uma empresa e o seu mercado. Além disso, determina o limite de atuação da empresa, seus objetivos e metas. O subsistema técnico é composto por máquinas, equipamentos, instalações, plantas e tecnologia, além de envolver aspectos físicos e temporais (BIAZZI Jr., 1994). O subsistema técnico pode ser considerado o cornerstone $^{2}$ de uma organização, pois dá suporte a toda estrutura organizacional e torna possível a realização de todas as operações de uma empresa.

Já o subsistema social, segundo Biazzi Jr. (1994), é composto por pessoas, relações, habilidades e aspirações pessoais. Ainda, é composto de interações entre os players internos e externos à organização (PASMORE e SHERWOOD, 1978, apud SMITH, FOX E RAMIREZ, 2010) ${ }^{3}$. Deste modo, o comportamento de cada player é interpretado e respondido por outros players envolvidos na situação (KINMAN, 2009).

O sistema sócio-técnico (que se caracteriza como um sistema aberto em constante interdependência) possui estratégias, procedimentos funcionais e outros fatores perceptíveis principalmente para o pessoal interno e é utilizado para gerar um sistema integrado de recuperação dos serviços. Similarmente, Davis (1977) propõe que a organização esteja direcionada para o alto desempenho, através de mudanças e aprendizados contínuos, estilo organizacional participativo e compartilhado pelos colaboradores.

\footnotetext{
${ }^{2}$ Pedra angular utilizada como base para construção dos alicerces de uma edificação.

${ }^{3}$ PASMORE, W. A.; SHERWOOD, J. J. Sociotechnical Systems: A Sourcebook. LaJolla, CA: University Associates, 1978.
} 
O sistema integrado de recuperação de serviços é composto por um conjunto cumulativo de componentes utilizados no processo de recuperação de serviços. Estabelece: a FORMALIDADE como as reclamações dos clientes são recebidas e tratadas internamente; a INFLUÊNCIA da reclamação dos consumidores nas estratégias de solução dos problemas; a INTENSIDADE que os funcionários são capacitados para lidar com os clientes e com as falhas ocorridas; o PODER e a liberdade que são dados aos funcionários para a solução de problemas; e os mecanismos de ACESSIBILIDADE que os clientes possuem para interagir com a organização e expor as falhas que ocorreram no processo e em função do serviço. (SMITH; FOX; RAMIREZ, 2010).

O que se supõe com a utilização deste sistema integrado de recuperação, segundo Smith, Fox e Ramirez (2010) é a obtenção de um clima organizacional favorável à recuperação dos serviços. Esse clima organizacional favorável permitiria a elevação do grau de confiança dos funcionários na sua capacidade de lidar com os problemas, ao mesmo tempo em que reduziria a relutância dos funcionários em se engajar no enfrentamento e solução dos problemas. Com isso, o resultado final seria a obtenção de um retorno positivo dos clientes em relação ao desempenho pessoal dos funcionários da empresa no processo de recuperação de um serviço.

\section{MODELO HIPOTÉTICO}

O modelo de recuperação de serviços de Smith, Fox e Ramirez (2010) foi utilizado nesse trabalho para averiguar a adequação do mesmo no setor turístico. A figura 1 representa as variáveis observadas e as cinco hipóteses que compõem o modelo proposto pelos autores. 
FIGURA 1 - MODELO DE RECUPERAÇÃO DE SERVIÇOS PELO SISTEMA SÓCIO-TÉCNICO

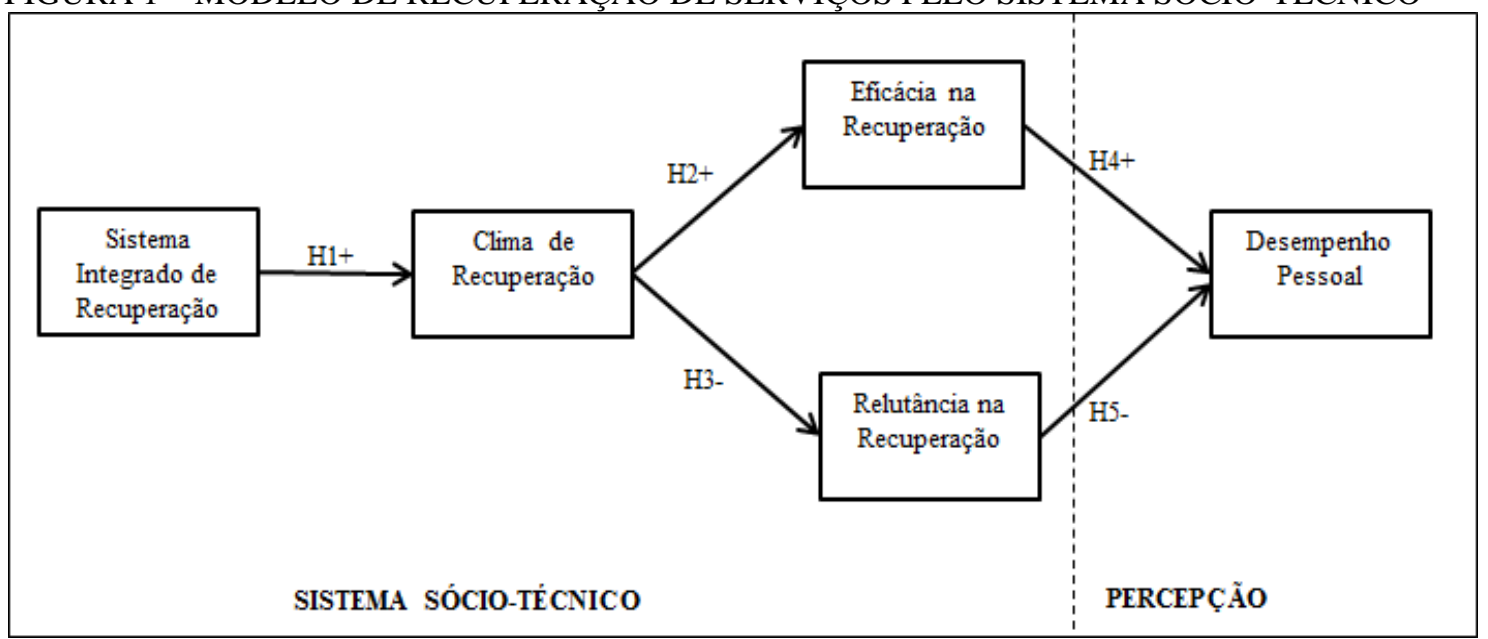

FONTE: ADAPTADO de SMITH, FOX e RAMIREZ (2010, p. 440).

I - A existência de um sistema integrado de recuperação de serviços propicia a existência de um clima organizacional favorável;

II - Um clima organizacional favorável à recuperação de serviços eleva o grau de confiança dos funcionários para lidar com as falhas;

III - Um clima organizacional favorável à recuperação de serviços reduz a relutância dos funcionários em se engajar na busca de soluções para as falhas;

IV - Um elevado grau de confiança proporciona o retorno positivo dos clientes em relação ao desempenho pessoal dos funcionários da empresa no processo de recuperação de um serviço;

$\mathrm{V}$ - A redução da relutância dos funcionários em se engajar na busca de soluções para as falhas proporciona o retorno positivo dos clientes em relação ao desempenho pessoal dos funcionários da empresa no processo de recuperação de um serviço.

O teste de uso do modelo para agências de turismo também seguiu outros procedimentos metodológicos, além do teste das hipóteses propostas, conforme relacionado no próximo tópico. 


\section{PROCEDIMENTOS METODOLÓGICOS}

O método utilizado para o alcance dos objetivos propostos, de acordo com Malhotra (2001), é conclusivo, utilizando uma abordagem quantitativa para análise dos dados, incluindo teste de hipóteses e avaliação de relações estudadas. Ainda, segundo o autor, a pesquisa é de cunho descritivo, buscando descrever características do setor de agência de turismo.

Para a realização desta pesquisa, foram consideradas como objeto de pesquisa as agências de turismo das principais cidades da região Centro-Oeste de Minas Gerais, desconsiderando aquelas que estavam trabalhando apenas com fretamento ou vendas de passagens. Dentro do perfil estabelecido, foram identificadas 35 agências de turismo com registro válido junto ao Ministério do Turismo e a coleta de dados foi feita transversalmente (MALHOTRA, 2001).

A definição da amostra, 32 agências, se deu de forma aleatória simples, considerando um erro amostral de $6 \%$ e nível de confiança de $95 \%$. Outra limitação da pesquisa é quanto à atuação do respondente. Foram considerados apenas os questionários respondidos por agentes de viagens e/ou gerentes que tinham contato direto com os clientes da agência. O questionário foi aplicado presencialmente pelos pesquisadores e respondido pelo próprio respondente em cada uma das agências.

Com base no exposto teórico e tomando por base as hipóteses levantadas na pesquisa realizada por Smith, Fox e Ramirez (2010), adaptou-se um instrumento para coletar dados que comprovassem ou refutassem as hipóteses propostas. Contudo, o enfoque se deu nas agências de turismo, por serem empresas prestadoras de serviços e catalisadoras das principais reclamações dos turistas, sejam elas com transporte, receptivos, hospedagem dentre outros estabelecimentos responsáveis pela efetiva prestação do serviço oferecido pelas agências.

A adaptação da escala de medição foi necessária para assegurar que os resultados representassem, efetivamente, um tipo específico de serviço. Contudo, preocupou-se em manter a base teórica para que a comparação entre os resultados também fosse válida. A escala utilizada está representada no Quadro 3, apresentado mais adiante. 
Desta forma, para análise do sistema de recuperação foram utilizados 3 itens para mensurar a formalidade, 4 itens para mensurar as influências, 4 itens para analisar a acessibilidade, 3 itens para analisar a intensidade e 4 itens para analisar o empowerment. Para analisar o construto eficácia da recuperação foram utilizados 4 itens e para o construto relutância foram utilizados 6 itens. O construto clima foi analisado a partir de 4 itens e o construto desempenho foi analisado com 5 itens. Os construtos foram medidos utilizando uma escala Likert de 5 pontos, atribuindo 1 ponto à discordância total da informação proposta e 5 pontos para a concordância total.

Testes estatísticos com apoio do software SPSS também serviram como suporte para o alcance dos resultados, dentre eles a análise das médias dos construtos e correlações entre as variáveis observadas.

A análise dos dados foi definida em comparação com os resultados alcançados por Smith, Fox e Ramirez (2010).

\section{RESULTADOS}

Os dados desse estudo foram analisados de forma descritiva e apresentaram as propriedades representadas no Quadro 3. Ainda, DP correspondente ao desvio padrão e Var. à variância encontrada.

QUADRO 3 - PROPRIEDADES DAS ESCALAS DE MEDIÇÃO.

\begin{tabular}{|c|c|c|c|}
\hline PROPRIEDADE DAS ESCALAS DE MEDIÇÃO & Média & DP & Var. \\
\hline \multicolumn{4}{|l|}{ RECUPERAÇÃO DE SERVIÇOS } \\
\hline \multicolumn{4}{|l|}{ FORMALIDADE } \\
\hline Na empresa as reclamações dos clientes são formalmente documentadas & 3,23 & 1,30 & 1,69 \\
\hline $\begin{array}{l}\mathrm{Na} \text { empresa existem orientações escritas para direcionar o processo de } \\
\text { reclamação dos clientes }\end{array}$ & 3,46 & 1,20 & 1,44 \\
\hline $\begin{array}{l}\text { Na empresa existem políticas e procedimentos que regem o processo de } \\
\text { recuperação de serviços }\end{array}$ & 3,77 & 1,09 & 1,19 \\
\hline \multicolumn{4}{|l|}{ INFLUÊENCIA } \\
\hline $\begin{array}{l}\text { Nosso processo de recuperação é muitas vezes alterado com base nas } \\
\text { reclamações do cliente }\end{array}$ & 4,08 & 0,49 & 0,24 \\
\hline $\begin{array}{l}\text { Nossa organização permite a sugestão do cliente para determinar como um erro } \\
\text { será corrigido }\end{array}$ & 4,00 & 0,71 & 0,50 \\
\hline $\begin{array}{l}\text { Nossos clientes têm uma grande influência sobre a forma como uma falha é } \\
\text { corrigida }\end{array}$ & 3,85 & 0,80 & 0,64 \\
\hline Nossa organização permite a participação do cliente na resolução do problema & 3,62 & 0,96 & 0,92 \\
\hline
\end{tabular}


Continuação...

\begin{tabular}{|c|c|c|c|}
\hline \multicolumn{4}{|l|}{ ACESSIBILIDADE } \\
\hline $\begin{array}{l}\text { Nossos clientes dispõem de vários mecanismos pelos quais eles podem reportar } \\
\text { falhas }\end{array}$ & 3,77 & 0,73 & 0,53 \\
\hline Nós fornecemos os meios pelos quais os clientes podem expressar suas queixas & 3,85 & 0,69 & 0,47 \\
\hline É fácil para os clientes nos notificar sobre os problemas que eles encontram & 4,31 & 0,63 & 0,40 \\
\hline $\begin{array}{l}\text { Clientes com problemas possuem muitas maneiras para nos informar sobre as } \\
\text { falhas }\end{array}$ & 4,00 & 0,71 & 0,50 \\
\hline \multicolumn{4}{|l|}{ INTENSIDADE } \\
\hline Eu fui treinado(a) para lidar com as reclamações dos clientes & 3,46 & 1,13 & 1,27 \\
\hline $\begin{array}{l}\text { Somos continuamente treinados sobre as formas de corrigir os erros que ocorrem } \\
\text { nos serviços }\end{array}$ & 3,23 & 1,17 & 1,36 \\
\hline $\begin{array}{l}\text { Somos regularmente informados sobre os benefícios, para toda equipe, da } \\
\text { resolução de problemas e a recuperação dos clientes insatisfeitos. }\end{array}$ & 3,38 & 1,26 & 1,59 \\
\hline \multicolumn{4}{|l|}{ EMPOWERMENT } \\
\hline $\begin{array}{l}\text { Estou apto a corrigir quaisquer problemas que eu encontro quando presto o } \\
\text { serviço }\end{array}$ & 3,92 & 0,95 & 0,91 \\
\hline É minha responsabilidade corrigir os erros cometidos na prestação de serviços & 4,08 & 1,19 & 1,41 \\
\hline Tenho poderes para corrigir as falhas de serviço & 3,38 & 1,33 & 1,76 \\
\hline Tenho permissão para usar o meu próprio julgamento na resolução de problemas & 3,00 & 1,08 & 1,17 \\
\hline \multicolumn{4}{|l|}{ EFICÁCIA DE RECUPERAÇÃO } \\
\hline $\begin{array}{l}\text { Quando confrontado com uma tarefa de recuperação, estou confiante que posso } \\
\text { lidar com isso }\end{array}$ & 3,92 & 0,86 & 0,74 \\
\hline Julgo que a minha capacidade de recuperação de um serviço é elevada & 3,54 & 0,78 & 0,60 \\
\hline $\begin{array}{l}\text { Quando defino uma meta para recuperar uma falha no serviço, normalmente } \\
\text { obtenho sucesso }\end{array}$ & 3,69 & 0,85 & 0,73 \\
\hline $\begin{array}{l}\text { Mesmo se eu falhar em uma tarefa de recuperação, continuo confiante que posso } \\
\text { ter sucesso da próxima vez }\end{array}$ & 4,23 & 0,73 & 0,53 \\
\hline \multicolumn{4}{|l|}{ RELUTÂNCIA DA RECUPERAÇÃO } \\
\hline Eu tento evitar as reclamações dos clientes sempre que possível & 4,54 & 0,66 & 0,44 \\
\hline Eu tento não ficar muito preocupado com as reclamações dos clientes & 2,54 & 1,33 & 1,77 \\
\hline Em caso de queixas, eu indico alguém para lidar com o problema & 2,31 & 1,32 & 1,73 \\
\hline $\begin{array}{l}\text { Quando os clientes reclamam, eu costumo ficar livre deles o mais rápido } \\
\text { possível }\end{array}$ & 1,92 & 1,12 & 1,24 \\
\hline $\begin{array}{l}\text { Quando um cliente reclama, eu costumo pensar em outra coisa para não me } \\
\text { envolver }\end{array}$ & 1,77 & 0,73 & 0,53 \\
\hline $\begin{array}{l}\text { Eu tento ficar longe de outros funcionários que tendem a causar a falha nos } \\
\text { serviços }\end{array}$ & 1,92 & 1,32 & 1,74 \\
\hline \multicolumn{4}{|l|}{ CLIMA DE RECUPERAÇÃO } \\
\hline Eu me sinto confortável em reportar as falhas de serviço para o meu supervisor & 3,85 & 0,99 & 0,97 \\
\hline Meu supervisor acredita que a recuperação do serviço é muito importante & 4,46 & 0,52 & 0,27 \\
\hline Meu supervisor é um bom auxílio para ajudar nas reclamações dos clientes & 4,23 & 0,60 & 0,36 \\
\hline Meu supervisor está empenhado em corrigir falhas de serviço & 4,31 & 0,85 & 0,73 \\
\hline \multicolumn{4}{|l|}{ DESEMPENHO PESSOAL } \\
\hline Os clientes apreciam a rapidez com que as falhas de serviço são respondidas & 3,69 & 1,11 & 1,23 \\
\hline Os Clientes estão satisfeitos com a minha maneira de lidar com as suas queixas & 4,15 & 0,69 & 0,47 \\
\hline Os clientes me agradecem por lidar com seus problemas & 4,15 & 0,90 & 0,81 \\
\hline $\begin{array}{l}\text { Os Clientes mencionam que estão satisfeitos com os meus esforços para resolver } \\
\text { os problemas }\end{array}$ & 4,15 & 0,69 & 0,47 \\
\hline $\begin{array}{l}\text { Os Clientes respondem positivamente pela maneira como eu lido com as } \\
\text { reclamações }\end{array}$ & $\mathrm{J}$ & 0,93 & 0,86 \\
\hline
\end{tabular}

FONTE: Autores 
O gráfico 1 demonstra as médias das escalas dos construtos avaliados na pesquisa. A maior média foi a de clima organizacional, seguida por desempenho, eficácia e sistema de recuperação. Já relutância, foi o construto que apresentou a menor média, demonstrando que os agentes de viagens entrevistados procuram não se envolver com as reclamações dos seus clientes e solucionar seus problemas.

Assim, a variação do conceito médio dos construtos corrobora os estudos realizados por Smith, Fox e Ramirez (2010). Percebe-se a tendência, exceto do construto relutância, a um comportamento médio comum dos construtos observados.

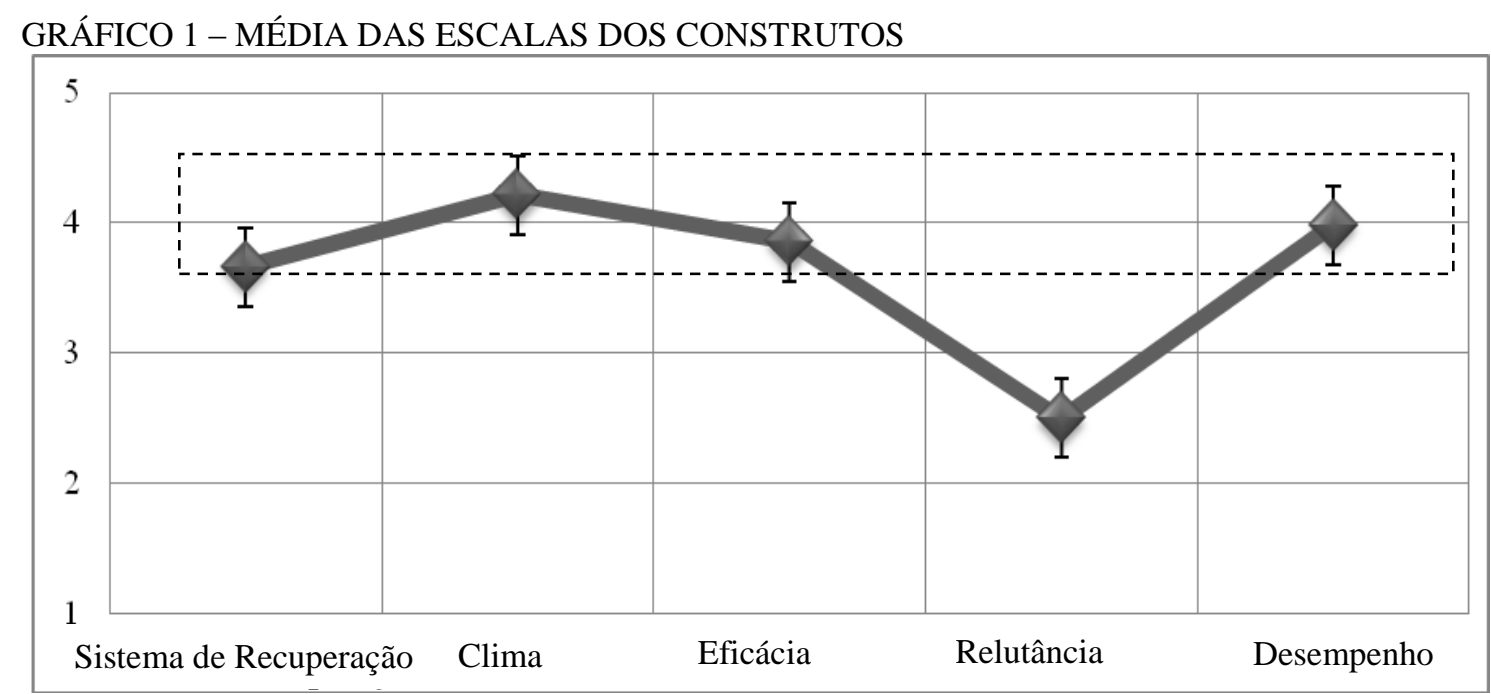

FONTE: Autores.

Foi possível notar que, apesar de todas as diferenças culturais e sociais das amostras, inclusive com a homogeneidade de uma amostra formada por profissionais que atuam em agências de turismo e a heterogeneidade de uma amostra composta por prestadores de serviços em geral, observou-se uma similaridade no comportamento médio dos respondentes.

Para a análise, foi utilizada a 'Correlação de Pearson'4 conforme é possível perceber no quadro 4. Dentre as cinco variáveis que compuseram o sistema de recuperação, apenas as variáveis Acessibilidade e Influência apresentaram uma forte correlação. As outras variáveis apresentaram fraca correlação ou não houve correlação.

Em outras palavras, os dados indicam que apenas o acesso dos clientes a reportar falhas (acessibilidade) e a possibilidade de influência dos clientes sobre a forma como o

\footnotetext{
${ }^{4}$ O coeficiente de correlação de Pearson é uma medida de associação bivariada (força) do grau de relacionamento entre duas variáveis (MOORE; McCABE, 2004).
} 
serviço será recuperado (influência) possuem relação significativa entre si $(0,72)$. Nenhuma outra combinação entre dois construtos estudados apresentou essa covariância de maneira significativa.

QUADRO 4 - CORRELAÇÃO ENTRE VARIÁVEIS QUE COMPÕEM O SISTEMA DE RECUPERAÇÃO DE FALHAS

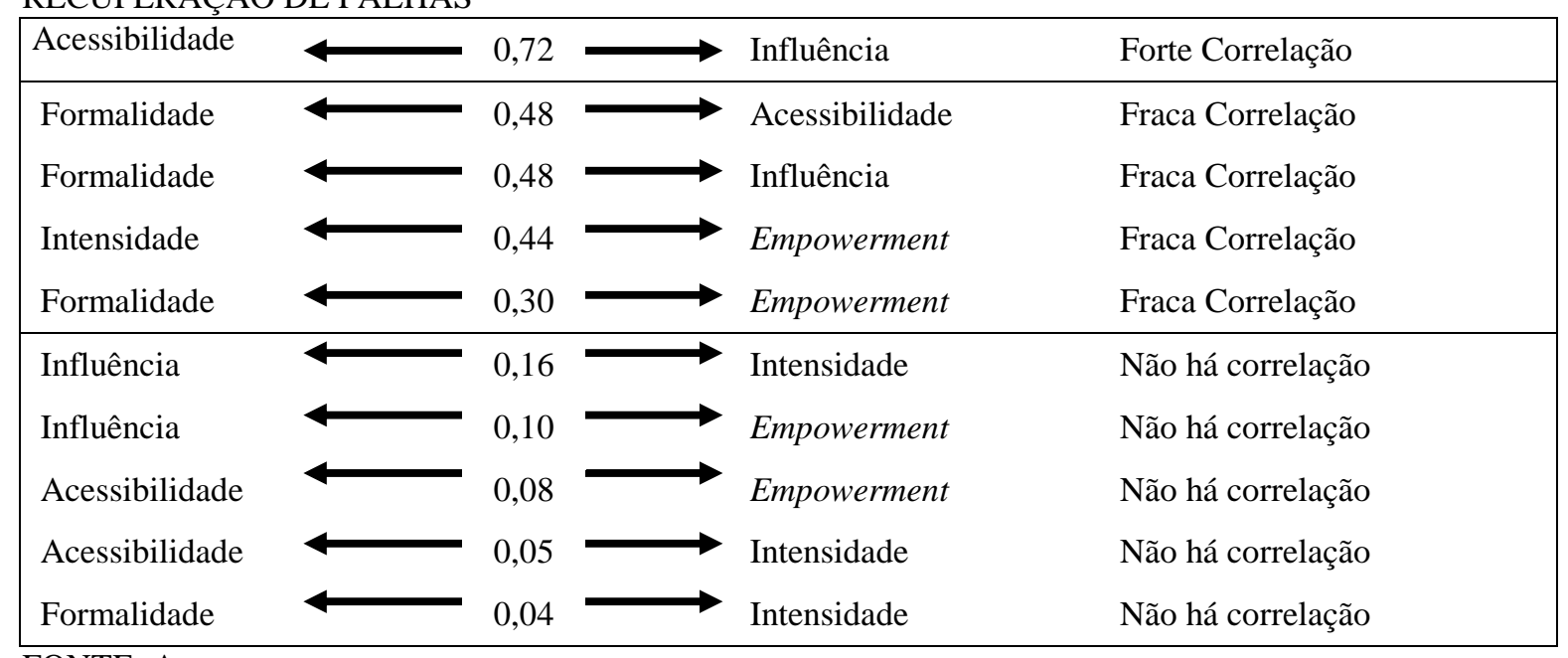

FONTE: Autores.

Contudo, a análise da correlação do conjunto das variáveis apresentou uma forte correlação com o sistema de recuperação, o que coincide em grande parte com o estudo de Smith, Fox e Ramirez (2010). Isso indica que todos os cinco construtos são importantes para se alcançar a recuperação de serviços em agências de viagem (Figura 2).

FIGURA 2 - CORRELAÇÃO ENTRE AS VARIÁVEIS E O SISTEMA DE RECUPERAÇÃO DE FALHAS

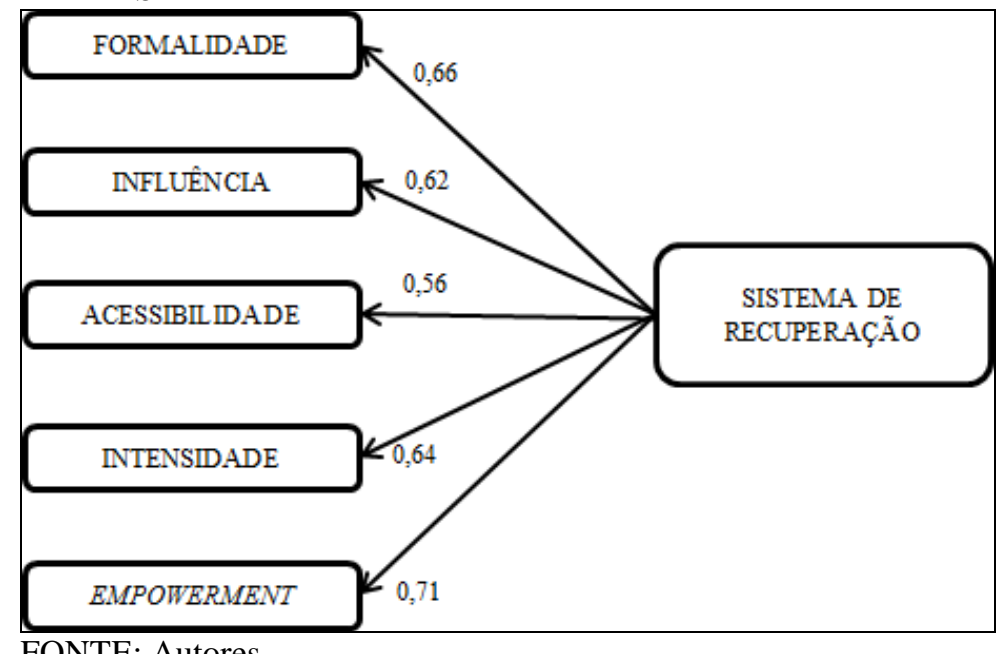


Um diferencial em destaque está na variável empowerment. Diferentemente da pesquisa de Smith, Fox e Ramirez (2010), onde esta variável apresentou uma fraca correlação, nesta pesquisa se destacou como a variável com correlação mais forte $(0,71)$.

Assim, para o contexto de agências de turismo, os profissionais assumem que precisam de poder e liberdade para a resolução de problemas. Com isso, empowerment é um indicador importante, uma vez que agências de turismo são intermediárias na prestação de serviços e nem sempre possuem esse poder para a resolução de falhas. Como exemplo, basta pensar nas dificuldades de atuação de uma agente de viagens em casos de atraso de voo ou um overbooking em um hotel.

Outra diferença notável entre o comportamento das variáveis está na correlação entre o sistema de recuperação e o clima de recuperação. (Figura 3)

FIGURA 3 - CORRELAÇÃO ENTRE AS VARIÁVEIS E O SISTEMA DE RECUPERAÇÃO DE FALHAS

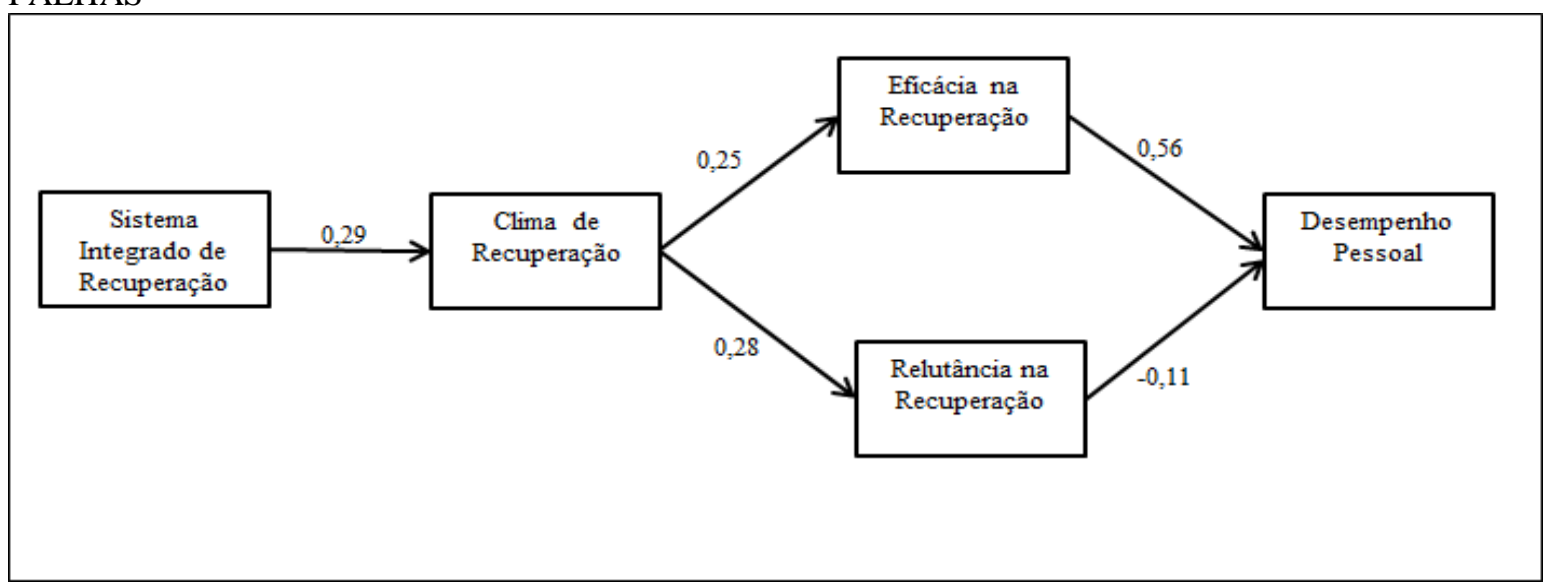

FONTE: Autores

Nas agências de turismo estudadas, a existência de um sistema de recuperação de serviços não contribui diretamente com a existência de um clima de recuperação favorável, refutando a primeira hipótese proposta neste estudo.

Além disso, não houve uma correlação significativa do construto Clima de Recuperação com a Eficácia da Recuperação ou com a Relutância da Recuperação. As duas hipóteses também foram refutadas. Em agências de turismo, o clima organizacional favorável à recuperação não eleva o grau de confiança dos funcionários e também não reduz a relutância deles em se engajar na busca de soluções para as falhas. 
A hipótese IV foi confirmada $(0,56)$, uma vez que a pesquisa demonstrou que a existência de um elevado grau de confiança proporciona o retorno positivo dos clientes em relação ao desempenho pessoal dos funcionários da empresa no processo de recuperação de um serviço.

Outra hipótese refutada foi a da existência de uma correlação negativa entre a relutância dos funcionários na busca de soluções para as falhas e um retorno positivo dos clientes. Imaginava-se que a diminuição da relutância em solucionar falhas poderia gerar um retorno positivo dos consumidores em relação ao desempenho pessoal dos funcionários da empresa. Contudo, os funcionários não demonstraram perceber tal comportamento por parte de seus clientes.

Um dado significativo obtido nesta pesquisa e que não havia sido considerado nas hipóteses elencadas, é a existência de uma forte correlação entre a existência de um sistema integrado de recuperação de serviços e a eficácia da recuperação. Isso indica que a existência deste sistema, ainda que não sugira uma melhoria no clima, propicia a elevação do grau de confiança dos funcionários para lidar com as falhas.

Finalmente, esse estudo encontrou muitas similaridades com o estudo de Smith, Fox e Ramirez (2010) indicando que o modelo pode ser utilizado para o contexto de agências de turismo. No entanto, mais pesquisas devem ser efetuadas para confirmar as disparidades encontradas entre o modelo de Smith, Fox e Ramirez (2010) e os resultados pormenorizados nesse estudo, em especial a forte correlação entre empowerment e o sistema de recuperação de serviços.

\section{CONSIDERAÇÕES FINAIS}

Diante dos resultados obtidos nesta pesquisa e diante da importância do processo de recuperação das falhas para retenção e fidelização de clientes, as agências de turismo deveriam fomentar um clima favorável para recuperação das falhas. Os funcionários destas empresas demonstraram perceber que existe uma relação direta entre a eficácia da recuperação e o retorno positivo do cliente. Demonstraram entender também, que possuindo maior poder e autonomia na solução das falhas, aprimorariam a existência de um sistema integrado de recuperação das falhas. 
Por fim, pela escassez de pesquisas específicas sobre o assunto percebe-se o quanto a preocupação com a visão do funcionário ainda é tratada de forma incipiente, mesmo sabendo da importância deste player para o desempenho organizacional.

A pesquisa demonstrou que a confiança proporciona o retorno positivo dos clientes em relação ao desempenho pessoal dos funcionários da empresa no processo de recuperação de um serviço. Santos e Fernandes (2008) também encontraram que a formação de confiança e lealdade do consumidor é afetada pela forma como as reclamações são resolvidas.

Porém, estudos como o de Pranic e Roehl (2012) apontam a necessidade de que a confiança também exista no fluxo contrário, ou seja, que a empresa confie em seus clientes. Para os autores, o empoderamento dos clientes pelas empresas implica na utilização de estratégias que deem informações suficientes, senso de controle e competência para a tomada de decisão dos clientes que necessitem recuperar uma falha. Dessa forma, os próprios consumidores seriam capazes de escolher uma das soluções que a empresa oferece para corrigir um erro.

Apesar da limitação geográfica e do tamanho da amostra, os resultados obtidos são significativos e indicam a necessidade de aprofundamento do tema. Considerando que os agentes de turismo são intermediários no processo de viagem, e que a insatisfação dos consumidores, muitas vezes, ocorre em função dos executores do serviço, recomenda-se ampliar esta pesquisa, realizando-a diretamente nos prestadores de serviços em cidades turísticas. Tendo em vista o gap de pesquisas acadêmicas em relação ao processo de recuperação de serviços, destaca-se a necessidade de maior visibilidade ao tema.

Para pesquisas futuras, é desejável que se investigue prestadores de serviço de outros setores no processo de recuperação das falhas sob a perspectiva do sistema sóciotécnico. Ainda, a ação do prestador do serviço tem um papel relevante no processo de recuperação de falhas e seu ponto de vista deve estar correlacionado com a expectativa do consumidor. Assim, é importante que a avaliação da díade prestador de serviçoconsumidor seja abordada em novas pesquisas visando um entendimento holístico de como as falhas afetam o comportamento e satisfação dos consumidores de serviços.

Por fim, em relação a implicações gerenciais, sugere-se que é preciso atuar quando um erro ocorre e até mesmo empresas intermediárias no processo de entrega do 
serviço devem se preocupar em recuperar suas falhas. Conforme Boshoff (2012), moderados níveis de recuperação de serviços produzem níveis ótimos de recuperação de serviços. Assim, de acordo com os estudos do autor bastaria uma compensação moderada (de $50 \%$ de reembolso) ou um pedido de desculpas moderado (dois pedidos de desculpas) durante a interação da recuperação de serviços entre empresa e cliente.

Portanto, as empresas devem deixar de tratar falhas de serviço com indiferença e feito isso, podem conquistar a confiança e a satisfação de seus clientes, aumentando a lealdade e possibilitando a recompra de seus serviços. Nesse sentido, é importante também, que os agentes de viagens sejam seletivos na escolha e indicação de fornecedores os quais sejam capazes de atender às necessidades dos clientes das agências de turismo.

\section{REFERÊNCIAS}

AMERICAN MARKETING ASSOCIATION - The American Marketing Association Releases New Definition for Marketing - Press Release - Chicago - 14 de Janeiro de 2008. Disponível em:

<http://www.marketingpower.com/AboutAMA/Documents/American\%20Marketing\%2 0Association\%20Releases\%20New\%20Definition\%20for\%20Marketing.pdf $>$. Acesso em: 05/04/2013.

BATESON, J. E. G.; HOFFMAN, K. D. Marketing de Serviços. Porto Alegre: Bookman, 2001.

BERRY, L. L. Serviços de Satisfação Máxima: Guia Prático de Ação. Rio de Janeiro: Campus, 1996.

BIAZZI Jr., F. A conveniência e a viabilidade da implementação do enfoque sóciotécnico nas empresas. Revista de Administração de Empresas, São Paulo, v. 34, n.1, p.30-37, Jan./Fev. 1994.

BITNER, M. J. Evaluating Service Encounters: The Effects of Physical Surroundings and Employee Responses. Journal of Marketing, p. 69-82, 1990.

BITNER, M. J.; BOOMS, H. B.; STANREAULT, M. The Service Encounter: Diagnosing Favorable and Unfavorable Incidents. Journal of Marketing, v. 54, p. 7184, Jan./1990. 
BOSHOFF, C. Can Service firms overdo service recovery? An assessment of nonlinearity in service recovery satisfaction. South African Business Management, v. 43, n. 3, 2012.

DAVIS, L. E. Evolving alternative organization designs: their sociotechnical bases. Human Relations, v. 3D, n. 3, p. 261-73,1977.

EMERY, F.; TRIST, E. The Causal Texture of Organizational Environments. Human Relations, v. 18, n. 1, p. 21-32, Feb.1965.

GRÖNROOS, C. Marketing: Gerenciamento de Serviços - a Competição por Serviços na Hora da Verdade. Rio de Janeiro: Campus, 2009.

Service Management and Marketing: a customer relationship management. Chichester: John Wiley \& Sons, 2. ed., 2000.

GUMMESSON, E. The New Marketing: Developing Long-Term Interactive Relationships. Long Range Planning, Great Britain, v. 20, n. 4, p. 10-20. Aug. 1987.

HOFFMAN, K. D.; BATESON, J. E. G. Princípios de Marketing de Serviços: Conceitos, estratégias e casos. São Paulo: Pioneira Thomson Learning, 2003.

KEITH, H. Consumer Satisfaction, Dissatisfaction, and Complaining Behavior. Journal of Social Issue. v. 47, n. 1, p. 109-110, 1991.

KINMAN, G. Emotional Labour and Strain in "Front-Line" Service Employees. Does Mode of Delivery Matter? Journal of Managerial Psychology, v. 24, n. 2, p. 118-135, 2009.

KOTLER, P. Administração de Marketing. São Paulo: Prentice Hall, 2009.

LAS CASAS, A. L. Administração de Marketing: conceitos, planejamento e aplicações à realidade brasileira. São Paulo: Atlas, 2006.

LIAO, H.; CHUANG, A. A Multilevel Investigation of Factors Influencing Employee Service Performance and Customer Outcomes. Academy of Management Journal, v. 47, n. 1, p. 41- 58, 2004.

LOVELOCK, C.; WRIGHT, L. Serviços: marketing e gestão. São Paulo: Saraiva, 2001.

MAlHOTRA, N. K. Pesquisa de Marketing: uma orientação aplicada. Porto Alegre: Bookman, 2001.

MOORE, D. S.; McCABE, G. Introduction to the practice of statistics. New York, Freeman, 2004.

McCARTHY, E. J. Basic Marketing: A Managerial Approach Homewood, IL: Irwin, 1960. 
PRANIC, L.; ROEHL, W. S. Rethinking Service Recovery: A Customer Empowerment (CE) Perspective. Journal of Business Economics and Management, v. 13, n. 2, p. 242-260, 2012.

SANTOS, C. P.; FERNANDES, D. V. D. H. A Recuperação de Serviços como Ferramenta de Relacionamento e Seu Impacto na Confiança e Lealdade dos Clientes. RAE - Revista de Administração de Empresas, v. 48, n. 1, jan.-mar, 2008.

SMITH, J. S.; FOX, G. L.; RAMIREZ, E. An Integrated Perspective of Service Recovery: A Sociotechnical Systems Approach. Journal of Service Research, p. 439452, Jul./2010.

TAX, S. S.; BROWN, S. W.; CHANDRASHEKARAN, M. Customer Evaluations of Service. Complaint Experiences: Implications for Relationship Marketing, Journal of Marketing, p. 60-76, Apr. 1998.

ZEITHAML, V. A.; BERRY, L. L.; PARASURAMAN, A. The Behavioral Consequences of Service Quality. The Journal of Marketing, v. 60, n. 2, p. 31-46. Apr. 1996.

ZEITHAML, V. A.; BITNER, M. J. Services Marketing. New York: McGraw-Hill, 2000.

Recebido em: 09-10-2012

Aprovado em: 08-11-2012 